\title{
Working cancer survivors' physical and mental characteristics compared to cancer-free workers in Japan: a nationwide general population-based study
}

\author{
Atsuhiko Ota ${ }^{1} \cdot{\text { Yuanying } \mathrm{Li}^{1} \cdot \text { Hiroshi Yatsuya }}^{1,2} \cdot \mathrm{Kozo}$ Tanno $^{3} \cdot$ Kiyomi Sakata $^{3} \cdot$ Kazumasa Yamagishi $^{4,5}$. \\ Hiroyasu Iso $^{4,6}$ • Nobufumi Yasuda ${ }^{7}$ Isao Saito ${ }^{8}$. Tadahiro Kato $^{9}$ • Kazuhiko Arima ${ }^{10}$ • Yoko Sou ${ }^{11}$ • Taichi Shimazu ${ }^{12}$. \\ Taiki Yamaji $^{12} \cdot$ Atsushi Goto $^{13} \cdot$ Manami Inoue $^{12} \cdot$ Motoki Iwasaki $^{12} \cdot$ Norie Sawada $^{12} \cdot$ Shoichiro Tsugane $^{12} \cdot$ for the \\ JPHC-NEXT Study Group
}

Received: 20 October 2020 / Accepted: 8 December 2020 / Published online: 12 January 2021

(C) The Author(s) 2021

\begin{abstract}
Purpose This study compared working cancer survivors' self-rated health status (SRHS), physical functional capacity, depressive symptoms, and happiness to those of cancer-free workers.

Methods A nationwide general population-based cross-sectional study on a sample of Japanese was conducted. Prevalence of deteriorated SRHS, restricted physical functional capacity, depressive symptoms, and perceived happiness were compared between working cancer survivors and cancer-free workers with multivariable logistic regression analysis adjusted for age and sociodemographic and health-related backgrounds.

Results Of the 28,311 male and 26,068 female workers, $977(3.5 \%)$ and 1267 (4.9\%) were cancer survivors, respectively. Working cancer survivors reported deteriorated SRHS more frequently than cancer-free workers: $21.3 \%$ vs. $13.8 \%$, multivariable-adjusted odds ratio (95\% confidence interval), 1.64 (1.39-1.95) for men, 23.8\% vs. 17.5\%, 1.34 (1.16-1.54) for women. Restricted physical functional capacity was reported more frequently in working cancer survivors than cancer-free workers: $6.8 \%$ vs. $2.6 \%, 1.76(1.34-2.32)$ for men, $4.9 \%$ vs. $2.0 \%, 2.06$ (1.56-2.71) for women. No significant difference was found for depressive symptoms: $21.6 \%$ vs. $22.9 \%$ in men, $30.0 \%$ vs. $28.5 \%$ in women. Working cancer survivors felt happiness more frequently than cancer-free survivors in men $(77.3 \%$ vs. $71.7 \%, 1.21(1.01-1.45))$ but not in women (76.1\% vs. $74.9 \%$ ).

Conclusions Working cancer survivors had worse SRHS and more restricted physical functional capacity than cancer-free workers. In men, working cancer survivors felt happiness more frequently than cancer-free workers.

Implications for Cancer Survivors Continuous support to improve cancer survivors' SRHS and physical functional capacity would be necessary even while they are working.
\end{abstract}

Atsuhiko Ota

ohtaa@fujita-hu.ac.jp

1 Department of Public Health, Fujita Health University School of Medicine, 1-98 Dengakugakubo, Kutsukake-cho, Toyoake, Aichi 470-1192, Japan

2 Department of Public Health and Health Systems, Nagoya University Graduate School of Medicine, Nagoya, Japan

3 Department of Hygiene and Preventive Medicine, School of Medicine, Iwate Medical University, Iwate, Japan

4 Department of Public Health Medicine, Faculty of Medicine, and Health Services Research and Development Centre, University of Tsukuba, Tsukuba, Japan

5 Ibaraki Western Medical Center, Chikusei, Japan

6 Department of Social and Environmental Medicine, Osaka University Graduate School of Medicine, Osaka, Japan
7 Department of Public Health, Kochi University Medical School, Kochi, Japan

8 Department of Public Health and Epidemiology, Faculty of Medicine, Oita University, Oita, Japan

9 Center for Education and Educational Research, Faculty of Education, Ehime University, Matsuyama, Japan

10 Department of Public Health, Nagasaki University Graduate School of Biomedical Sciences, Nagasaki, Japan

11 Ken'ou Healthcare Office, Nagasaki Prefectural Government, Nagasaki, Japan

12 Epidemiology and Prevention Group, Center for Public Health Sciences, National Cancer Center, Tokyo, Japan

13 Department of Health Data Science, Yokohama City University Graduate School of Data Science, Yokohama, Japan 
Keywords Work $\cdot$ Cancer survivors $\cdot$ Self-rated health status $\cdot$ Physical functional capacity $\cdot$ Depressive symptoms $\cdot$ Happiness

\section{Introduction}

In Japan, the age-adjusted cancer mortality rate has been decreasing over the past few decades; the latest 5 -year relative survival rate for cancer is estimated to be $62.1 \%$ [1]. Consequently, questions on how to improve health and wellbeing of cancer survivors have attracted more clinical attention. Researchers addressed cancer survivors' health-related quality of life (HRQOL). Existing research generally revealed the prognostic ability of deteriorated HRQOL in cancer survivors [2, 3]. Individual-level HRQOL includes physical and mental health perceptions and their correlates, such as health risks and conditions and functional status [4]. Self-rated health status (SRHS), physical functional capacity, depressive symptoms, and happiness (regarded as affective well-being [5, 6]) form a component of HRQOL. Cancer survivors claimed deteriorated SRHS [6, 7], restricted physical functional capacity $[6,7]$, depressive symptoms $[6,8]$, and unhappiness [6] more frequently than the cancer-free individuals. Deteriorated SRHS $[9,10]$, decreased physical activity $[11,12]$, and depression [13] worsened the prognosis of cancer survivors.

There is limited evidence regarding working cancer survivors' SRHS, physical functional capacity, depressive symptoms, and happiness. Working is a form of societal involvement for the working-age; thus, the Japanese government and employers must assist working cancer survivors in finding a balance between work and treatment under the Cancer Control Act [1]. The return-to-work rates among cancer survivors reportedly ranged from 53.8 to $95.2 \%$ in Japan [14]. Compared to cancer survivors who were not working, those who were working were more likely to have better SRHS $[15,16]$ and physical functional capacity $[17,18]$, and a lower prevalence of depression [19-21].

It was not well addressed whether the prevalence of poor SRHS, restricted physical functional capacity, depressive symptoms, and happiness differed between working cancer survivors and cancer-free workers. In a Japanese study, compared to cancer-free workers, working cancer survivors showed a significantly higher prevalence of deteriorated SRHS in men, of restricted physical functional capacity in both men and women, but not of unhappiness in either men or women [22]. Similarly, working cancer survivors' SRHS was worse than that of cancer-free workers in Norway [23]. It is controversial whether the prevalence of depressive symptoms differed between working cancer survivors and cancerfree workers [24]. Few studies examined the differences in happiness between working cancer survivors and cancer-free workers.

Therefore, we conducted a cross-sectional analysis to compare the prevalence of deteriorated SRHS, restricted physical functional capacity, depressive symptoms, and happiness between working cancer survivors and cancer-free workers at the national level, using a nationwide general population sample.

\section{Methods}

\section{Study design and sample}

We conducted a cross-sectional investigation using baseline data from the Japan Public Health Center-based Prospective Study for the Next Generation (JPHC-NEXT Study). Details of its design and participants are reported elsewhere [25]. Eligible participants were 261,939 residents $(130,602$ men and 131,337 women) aged 40-74 in 16 municipalities of seven prefectures across Japan. The baseline survey was conducted between 2011 and 2016. Of the 114,105 individuals (52,566 men and 61,539 women) who responded to the questionnaire, 64,960 individuals (33,632 men and 31,328 women) fulfilled the inclusion criteria of the present study: aged 40-65 years and workers at baseline. Workers were defined as those who did not declare themselves to be an unemployed individual or a homemaker. After excluding 10,581 individuals with missing responses for any of the study variables, we analyzed data from 54,379 individuals (28,311 men and 26,068 women).

\section{Study variables}

All data were collected through a questionnaire. Participants were asked about their cancer history, SRHS, physical functional capacity, depressive symptoms, happiness, and sociodemographic and health-related backgrounds.

\section{Definition of working cancer survivors and cancer- free workers}

We used two questions to define the working cancer survivors and cancer-free workers. The first question referred to working status. The participants chose their occupation from the following options: unemployed, homemaker, professional or technical work, administrative work, clerk, sales, service, security, agriculture or fishery, transportation or telecommunications, industrial operation/management, other. Those who did not choose unemployed or homemaker were regarded as a worker. Those who chose the options of professional or technical work, administrative work, clerk, sales, or service were regarded as white-collar workers, while those who chose security, agriculture or fishery, transportation or 
telecommunications, industrial operation/management, or other were regarded as blue-collar workers. The second question asked whether they had been diagnosed with and treated for cancer. The applicable options included "stomach cancer," "colorectal cancer," "lung cancer," "liver cancer," "breast cancer," "prostate cancer," and "other cancer."

Participants who reported to be a worker and had been diagnosed with and treated for cancer were regarded as working cancer survivors. Participants who reported to be a worker and had not been diagnosed with cancer were regarded as cancer-free workers.

\section{SRHS}

Participants responded to the question, "What do you think of your general health status during the last month?" Subsequently, participants were dichotomized, according to their responses. Those who self-reported "excellent," "very good," or "good" were regarded as having fine SRHS, while those who reported "a little poor" or "poor" were regarded as having deteriorated SRHS.

\section{Restricted physical functional capacity}

Restricted physical functional capacity was assessed using the Scale of Independence in Daily Living for the Disabled Elderly published by the Ministry of Health, Labour and Welfare, Japan [26]. Functional capacity impairment is a multidimensional concept that includes sensory loss, impaired mobility, vascular problems, gait impairments, difficulties with activities of daily living (ADLs), and disturbances in bodily systems [27]. A correlation between the bad scale scores and poor ADLs was confirmed [28]. In the present study, participants self-assessed their functional capacity by choosing the most appropriate one from nine options ranging from having no physical disability to being bed-bound. Participants who did not choose the option "I have no physical disability currently for daily living," were regarded as having restricted physical functional capacity. The other eight options included "I have some disability, I do not need any care to live independently, and (1) I can go out of my house alone using public transportation or (2) I can go out by myself only within the neighborhood," "I can live independently in my house without care, I need care to go out of my house, and (3) I spend the daytime off the bed or (4) I spend most of the daytime sleeping on and off in bed," "I need care to live in my house, I can keep a sitting position by myself although I usually spend the daytime on the bed, and (5) I can move to a wheelchair by myself or (6) I cannot move to a wheelchair by myself," and "I spend the whole day on the bed, I need care with excreting, eating, and dressing, and (7) I can roll over in bed or (8) I cannot roll over in bed by myself."

\section{Depressive symptoms}

In the present study, we used a modified 11-item Center for Epidemiological Studies Depression (CES-D) Scale [29, 30]. A score of 8 or higher was regarded as presence of depressive symptoms.

\section{Happiness}

A single question- " "How happy do you feel about your life?"-was used to assess happiness. Participants were dichotomized according to their responses; those who replied "very happy" or "happy" were regarded as experiencing happiness, while those who replied "neither happy nor unhappy" or "unhappy" were not.

\section{Sociodemographic and health-related backgrounds}

We assessed participants' age, occupation, type of employment (regular, irregular [part-time worker, contract employee, temporary staff], self-employed, or businesspeople), educational background (junior or senior high school, university, junior college, or vocational school), yearly household income $(<3$, 3-6, 6-9, 9 $\leq$ million Japanese Yen [JPY]), current use of prescription medicine, social support, perceived stress, body mass index (calculated based on self-reported height and weight), smoking status (never, ex-, or current smokers), and alcohol drinking status (never, ex-, or current drinkers). As of October 2020, $100 \mathrm{JPY}$ is approximately equivalent to 0.9 USD. We asked the subjects whether they were using prescription medicine for hypertension, dyslipidemia, diabetes, gout, osteoporosis, stroke, depression, blood coagulation, and other diseases. Social support was assessed with the ENRICHD Social Support Instrument (ESSI) [31, 32]. A higher total score indicates higher availability of social support. Perceived stress during the last month was assessed with the four-item Perceived Stress Scale (PSS-4) [33, 34]. A higher total score indicates higher perceived stress. The amounts of alcohol consumption per day ( $\leq$ or $>23$ g a day) of current drinkers were calculated, using their self-reports on the type and amount of alcoholic drinks they were daily consuming.

\section{Statistical analysis}

We summarized participants' sociodemographic and healthrelated backgrounds and compared them by cancer history using a $t$ test and chi-square test. Residual analysis was applied when chi-square test found a significant statistical difference. Multivariable logistic regression analysis was used to calculate odds ratios (ORs) and $95 \%$ confidence intervals (CIs) of working cancer survivors compared to cancer-free workers for restricted functional capacity, SRHS, the presence of depressive symptoms, and happiness. Two multivariable 
models were constructed. In Model 1, we adjusted for age and resident area. In Model 2, we additionally adjusted for type of employment, educational background, yearly household income, current use of prescription medicine, ESSI and PSS-4 scores, body mass index, and smoking and drinking statuses. These factors are supposed to affect functional capacity, SRHS, depressive symptoms, and happiness [5, 35-40]. We performed all the statistical analyses separately by gender since the existing sources show the cancer incidence and the frequency of cancer sites differing greatly by gender [1]. All analyses were conducted using SAS for Windows, version 9.4 (SAS/STAT 14.3; SAS Institute, Cary, NC, USA).

\section{Results}

Of 28,311 men and 26,068 women, 977 (3.5\%) and 1267 $(4.9 \%)$ were working cancer survivors, respectively. There were more working cancer survivors among women than men $(p<0.001)$. The most frequent response for the cancer site was "other" (32.1\% in men and $44.0 \%$ in women). Other than that, frequent cancer sites were stomach $(25.7 \%)$, colorectum $(22.2 \%)$, prostate $(13.5 \%)$, lung $(7.2 \%)$, and liver $(3.4 \%)$ for men and breast $(38.2 \%)$, colorectum $(9.0 \%)$, stomach (7.9\%), lung (3.9\%), and liver $(0.6 \%)$ for women. In the present study, $3.9 \%$ of male and $3.3 \%$ of female cancer survivors declared two or more cancer sites.

Participants' sociodemographic and health-related backgrounds are summarized in Table 1 and Supplementary Table 1. For both genders, working cancer survivors were older, self-employed or businesspeople more frequently, using prescription medicine more frequently, and quit smoking and drinking more frequently than cancer-free workers. Only in men, working cancer survivors included blue-collar workers more frequently, were less educated, had lower household income, and presented higher ESSI scores and lower PSS-4 scores than cancer-free workers.

Both in men (Table 2) and women (Table 3), working cancer survivors reported deteriorated SRHS and restricted physical functional capacity more frequently than cancerfree workers. There was no significant difference in the prevalence of participants with the presence of depressive symptoms between working cancer survivors and cancer-free workers both in men and women. Working cancer survivors were experiencing happiness more frequently than cancer-free workers in men, but not in women.

\section{Discussion}

We described the prevalence of deteriorated SRHS, restricted physical functional capacity, the presence of depressive symptoms, and happiness, and compared them between working cancer survivors and cancer-free workers. Working cancer survivors were self-employed or businesspeople more frequently than cancer-free workers. In men, blue-collar workers were more frequent in working cancer survivors than in cancer-free workers. Experiencing cancer could perhaps change the way of employment and working, although a cross-sectional examination cannot conclude the causality. Working cancer survivors exhibited a higher prevalence of deteriorated SRHS and restricted physical functional capacity than cancer-free workers. Meanwhile, there was no significant difference in the prevalence of the presence of depressive symptoms between working cancer survivors and cancer-free workers. Working cancer survivors felt happiness more frequently than cancer-free workers in men. A strength of the present study is that we indicated working cancer survivors' SRHS, physical functional capacity, depressive symptoms, and happiness and compared to cancer-free workers at the national level by analyzing the nationwide general population sample.

\section{SRHS}

The prevalence of deteriorated SRHS in all the subjects was approximately $15 \%$. It is consistent with a study of another Japanese general population sample of the same age [40].

Deteriorated SRHS was reported more frequently in working cancer survivors in the present study. This is concordant with previous studies with smaller-sized samples that showed a significant association between having cancer history and poor SRHS $[22,23]$. The present study had a large sample size, which made the association more prominent. The present findings confirmed that, even if cancer survivors were working, they reported deteriorated SRHS more often than cancer-free workers. Although the crosssectional nature of the present study would not allow interpretation of causality, the present findings would suggest that working is not the absolute solution to improve the SRHS of cancer survivors. It was reported that poor SRHS increased the mortality of cancer survivors $[9,10]$. Thus, continuous support would be necessary to improve cancer survivors' SRHS and prognosis, even while they are working.

\section{Restricted physical functional capacity}

Restricted physical functional capacity was found more often in cancer survivors than in cancer-free workers. This finding is concordant with a previous Japanese study [22]. It is suggested that some cancer survivors' physical functional capacity remained impaired even while they were working.

The present finding would partly be supported by the existing literature. Reviews reported that breast cancer 
Table 1 Sociodemographic and health-related backgrounds of working cancer survivors and cancer-free workers according to sex, JPHC-NEXT Study, 2011-2016, Japan

\begin{tabular}{|c|c|c|c|c|c|c|}
\hline \multirow[t]{2}{*}{ Characteristic } & \multicolumn{3}{|l|}{ Men $(n=28,311)$} & \multicolumn{3}{|c|}{ Women $(n=26,068)$} \\
\hline & $\begin{array}{l}\text { Working cancer } \\
\text { survivors } \\
(n=977)\end{array}$ & $\begin{array}{l}\text { Cancer-free } \\
\text { workers } \\
(n=27,334)\end{array}$ & $p$ value & $\begin{array}{l}\text { Working cancer } \\
\text { survivors } \\
(n=1267)\end{array}$ & $\begin{array}{l}\text { Cancer-free } \\
\text { workers } \\
(n=24,801)\end{array}$ & $p$ value \\
\hline Age (mean, standard deviation) & $58.4(5.8)$ & $53.2(7.5)$ & $<0.001$ & $54.5(6.8)$ & $52.4(7.2)$ & $<0.001$ \\
\hline \multicolumn{7}{|l|}{ Occupation $^{\text {a) }}$} \\
\hline White-collar & $569(58.2)$ & $16,950(62.0)$ & 0.010 & $934(73.7)$ & $18,087(72.9)$ & 0.618 \\
\hline Blue-collar & $403(41.2)$ & $10,126(37.0)$ & & $327(25.8)$ & $6544(26.4)$ & \\
\hline \multicolumn{7}{|l|}{ Type of employment } \\
\hline Regular & $418(42.8)^{* * *}$ & $15,203(55.6)$ & $<0.001$ & $452(35.7)$ & $8876(35.8)$ & 0.023 \\
\hline Irregular & $176(18.0)^{* *}$ & $3920(14.3)$ & & $534(42.1)^{*}$ & $11,155(45.0)$ & \\
\hline Self-employed/ businesspeople & $383(39.2)^{* * *}$ & $8211(30.0)$ & & $281(22.2)^{* *}$ & $4770(19.2)$ & \\
\hline \multicolumn{7}{|l|}{ Educational background } \\
\hline Junior/senior high school & $641(65.6)$ & $16,983(62.1)$ & 0.028 & $749(59.1)$ & $14,391(58.0)$ & 0.443 \\
\hline $\begin{array}{l}\text { University, junior college, vocational } \\
\text { school }\end{array}$ & $336(34.4)$ & $10,351(37.9)$ & & $518(40.9)$ & $10,410(42.0)$ & \\
\hline \multicolumn{7}{|l|}{ Household income (million Japanese yen) } \\
\hline Less than 3 & $280(28.7)^{* *}$ & $6721(24.6)$ & 0.010 & $432(34.1)$ & 9149 (36.9) & 0.254 \\
\hline 3 through 6 & $383(39.2)^{* *}$ & $11,872(43.4)$ & & $486(38.4)$ & $9071(36.6)$ & \\
\hline 6 through 9 & $205(21.0)$ & $5949(21.8)$ & & $222(17.5)$ & $4177(16.8)$ & \\
\hline 9 or greater & $109(11.2)$ & $2792(10.2)$ & & $127(10.0)$ & $2404(9.7)$ & \\
\hline Use of prescription medicine & $575(58.9)$ & $9969(36.5)$ & $<0.001$ & $651(51.4)$ & $7938(32.0)$ & $<0.001$ \\
\hline Social support (ESSI score) & $27.5(6.4)$ & $26.2(7.2)$ & 0.002 & $27.2(6.4)$ & $27.1(6.3)$ & 0.952 \\
\hline Perceived stress (PSS-4 score) & $6.8(2.6)$ & $7.0(2.6)$ & $<0.001$ & $7.5(2.7)$ & $7.5(2.7)$ & 0.693 \\
\hline Body mass index & $23.3(3.2)$ & $24.2(15.1)$ & 0.066 & $22.3(3.5)$ & $22.9(27.7)$ & 0.376 \\
\hline \multicolumn{7}{|l|}{ Smoking } \\
\hline Current smoker & $284(29.1)^{* * *}$ & $10,654(39.0)$ & $<0.001$ & $126(9.9)$ & $2533(10.2)$ & 0.035 \\
\hline Ex-smoker & $552(56.5)^{* * *}$ & $11,226(41.1)$ & & $162(12.8)^{* *}$ & $2602(10.5)$ & \\
\hline Never smoker & $141(14.4)^{* * *}$ & $5454(20.0)$ & & $979(77.3)$ & $19,666(79.3)$ & \\
\hline \multicolumn{7}{|l|}{ Alcohol drinking } \\
\hline Current drinker (>23 g/day) & $457(46.8)$ & $12,729(46.6)$ & $<0.001$ & $102(8.1)$ & $2193(8.8)$ & $<0.001$ \\
\hline Current drinker ( $\leq 23 \mathrm{~g} /$ day $)$ & $319(32.7)^{*}$ & $9994(36.6)$ & & $546(43.1)$ & $11,015(44.4)$ & \\
\hline Ex-drinker & $90(9.2)^{* * *}$ & $812(3.0)$ & & $51(4.0)^{* * *}$ & $558(2.2)$ & \\
\hline Never drinker & $111(11.4)^{*}$ & $3799(13.9)$ & & $568(44.8)$ & $11,035(44.5)$ & \\
\hline
\end{tabular}

ESSI: ENRICHD Social Support Instrument. PSS-4: 4-item Perceived Stress Scale

Figures are presented as the number and proportion (\%), except for age

Asterisks $* * *$, and $* * *$ indicate $p$ values of less than $0.05,0.01$, and 0.001 , respectively, by residual analysis

a) The statistic excluded those who were dedicated to two or more occupations: $5(0.5 \%)$ male working cancer survivors, 258 ( $0.9 \%)$ male cancer-free workers, $6(0.5 \%)$ female working cancer survivors, and $170(0.7 \%)$ female cancer-free workers

patients could have decreased strength, mobility, fatigue, and difficulties with physical tasks [18, 41, 42]. Oncotherapy could lead to a long-term decrease in the physical functional capacity in gastric and colorectal cancer patients [43, 44]. Chemotherapy, hormonal therapy, and radiation therapy could induce bone loss and muscle weakness in survivors of breast or prostate cancer, which were prevalent in working-age individuals $[45,46]$. Oncotherapy could also cause cardiovascular side-effects [47, 48] and peripheral neuropathy [49]. Such physical changes would result in restricted physical functional capacity of working cancer survivors.

Since the Scale of Independence in Daily Living for the Disabled Elderly was developed to assess the physical functional capacity of elderly people, there is little evidence on whether the scale holds the validity for the middle-aged individuals. However, the scale items are easily understandable for the working-age participants to respond regarding their physical function. 
Table 2 Adjusted odds ratios (AORs) of male working cancer survivors $(n=977)$ compared to cancer-free workers $(n=27,334)$, in terms of self-rated health status (SRHS), restricted physical functional capacity, depressive symptoms, and happiness, JPHC-

NEXT Study, 2011-2016, Japan

\begin{tabular}{|c|c|c|c|}
\hline \multirow[t]{2}{*}{ Dependent variable } & \multirow[t]{2}{*}{$N(\%)$} & \multicolumn{2}{|l|}{ AOR $(95 \% \mathrm{CI})$} \\
\hline & & Model 1 & Model 2 \\
\hline \multicolumn{4}{|l|}{ Deteriorated SRHS } \\
\hline Cancer-free workers & $3775(13.8)$ & 1 & 1 \\
\hline Working cancer survivors & $208(21.3)$ & $1.79(1.53-2.10)^{* * *}$ & $1.64(1.39-1.95)^{* * *}$ \\
\hline \multicolumn{4}{|c|}{ Restricted physical functional capacity } \\
\hline Cancer-free workers & $715(2.6)$ & 1 & 1 \\
\hline Working cancer survivors & $66(6.8)$ & $2.15(1.65-2.80)^{* * *}$ & $1.76(1.34-2.32)^{* * *}$ \\
\hline \multicolumn{4}{|l|}{ Depressive symptoms } \\
\hline Cancer-free workers & $6266(22.9)$ & 1 & 1 \\
\hline Working cancer survivors & $211(21.6)$ & $1.11(0.95-1.30)$ & $1.17(0.97-1.41)$ \\
\hline \multicolumn{4}{|l|}{ Happiness } \\
\hline Cancer-free workers & $19,612(71.7)$ & 1 & 1 \\
\hline Working cancer survivors & $755(77.3)$ & $1.26(1.09-1.47)^{* *}$ & $1.21(1.01-1.45)^{*}$ \\
\hline
\end{tabular}

$C I$, confidence interval. Adjusted odds ratios were calculated with multiple logistic regression analysis. Asterisks $*$, **, and $* * *$ indicate $p$ values of less than $0.05,0.01$, and 0.001 , respectively. In Model 1 , we adjusted for age and resident area. In Model 2, in addition to the factors in Model 1, we adjusted for type of employment, educational background, yearly household income, use of prescription medicine, scores of the ENRICHD Social Support Instrument and the 4-item Perceived Stress Scale, body mass index, smoking, and alcohol drinking

\section{Presence of depressive symptoms}

The prevalence of those having depressive symptoms was approximately $20 \%$ in men and $25 \%$ in women in the present study. The present findings, i.e., the prevalence of those having depressive symptoms and its association with cancer history, little changed even when the cut-off score of our modified CES-D scale was set at 7 or higher as a research group previously proposed (data not shown) [50]. Previous studies addressing full-time workers in Japan, who were supposed to feel very stressed, found a higher prevalence of CESD-assessed depressive symptoms, with $25 \%$ and $34 \%$ in men and women, respectively, in one study [51], and 30\% (male subjects: $73 \%$ ) in another [52]. We thus believe our modified
Table 3 Adjusted odds ratios (AORs) of female working cancer survivors $(n=1267)$ compared to cancer-free workers $(n=24,801)$, in terms of self-rated health status (SRHS), restricted physical functional capacity, depressive symptoms, and happiness, JPHCNEXT Study, 2011-2016, Japan

\begin{tabular}{|c|c|c|c|}
\hline \multirow[t]{2}{*}{ Dependent variable } & \multirow[t]{2}{*}{$N(\%)$} & \multicolumn{2}{|l|}{ AOR $(95 \% \mathrm{CI})$} \\
\hline & & Model 1 & Model 2 \\
\hline \multicolumn{4}{|l|}{ Deteriorated SRHS } \\
\hline Cancer-free workers & $4336(17.5)$ & 1 & 1 \\
\hline Working cancer survivors & $301(23.8)$ & $1.52(1.33-1.74)^{* * *}$ & $1.34(1.16-1.54)^{* * *}$ \\
\hline \multicolumn{4}{|c|}{ Restricted physical functional capacity } \\
\hline Cancer-free workers & $484(2.0)$ & 1 & 1 \\
\hline Working cancer survivors & $62(4.9)$ & $2.33(1.77-3.06)^{* * *}$ & $2.06(1.56-2.71)^{* * * *}$ \\
\hline \multicolumn{4}{|l|}{ Depressive symptoms } \\
\hline Cancer-free workers & $7068(28.5)$ & 1 & 1 \\
\hline Working cancer survivors & $380(30.0)$ & $1.12(0.99-1.27)$ & $1.06(0.91-1.23)$ \\
\hline \multicolumn{4}{|l|}{ Happiness } \\
\hline Cancer-free workers & $18,581(74.9)$ & 1 & 1 \\
\hline Working cancer survivors & $964(76.1)$ & $1.05(0.92-1.20)$ & $1.12(0.96-1.31)$ \\
\hline
\end{tabular}

CI, confidence interval. Adjusted odds ratios were calculated with multiple logistic regression analysis. Asterisk *** indicates $p$ values of less than 0.001. In Model 1, we adjusted for age and resident area. In Model 2, in addition to the factors in Model 1, we adjusted for type of employment, educational background, yearly household income, use of prescription medicine, scores of the ENRICHD Social Support Instrument and the 4-item Perceived Stress Scale, body mass index, smoking, and alcohol drinking 
CES-D scale appropriate for evaluating the prevalence of those having depressive symptoms. However, a study limitation is that we have not yet validated our scale.

The prevalence of the presence of depressive symptoms did not differ between working cancer survivors and cancer-free workers in the present study. Previous studies that compared the prevalence between working and non-working cancer survivors exhibited inconsistent results [24]. A study of breast cancer survivors in the USA reported that the prevalence of those having depressive symptoms assessed by the CES-D did not differ between those who were and were not working [53]. In contrast, the prevalence reportedly differs between employment status in a study of hepatocellular carcinoma survivors in Japan [19].

The lack of information about the date of cancer diagnosis led to heterogeneous duration of cancer survivorship among the study participants, which might account for the insignificant difference in the prevalence of depression symptoms between working cancer survivors and cancer-free workers. Depression prevalence in cancer survivors has been shown to decrease over time after cancer diagnosis [24, 39, 54]. In addition, the prevalence of depressive symptoms in working cancer survivors might be underestimated. Some cancer patients with depressive symptoms might not have been willing to participate in the survey or might have died since depression was related to increased all-cause mortality in cancer survivors [13]. This could have decreased the prevalence of depressive symptoms in working cancer survivors, diminishing the difference from that in cancer-free workers.

\section{Happiness}

Over $70 \%$ of the participants felt happiness in the present study. A similar proportion was reported in previous studies conducted in occupational settings in Japan [22, 55]. In general, women in Japan are more likely to report their feeling of happiness than men [56]. This was true for cancer-free workers in the present study; however, the trend was reversed for working cancer survivors.

In the present study, only male cancer survivors felt happiness more frequently than cancer-free workers. It was suggested that a role as a breadwinner was associated with happiness in men in Japan [56]. In that context, working might have contributed to increasing happiness of male working cancer survivors in Japan. In contrast, a Korean study reported that having purpose and hope in life was but the working status was not associated with happiness among breast cancer survivors [57]. The latter finding is concordant with our finding. Working might not instantly increase happiness among female cancer survivors.

It was reported in the USA and Brazil that cancer survivors were happier than the general population after adjustment for age, sex, and other demographic characteristics $[58,59]$. In contrast, a previous Japanese study with a smaller-sized sample found no significant difference in the prevalence of feeling happiness between working cancer survivors and cancer-free workers in both male and female local government employees [22].

A study limitation is that we only assessed happiness with a single question - "How happy do you feel about your life?"which may have been too simple to assess happiness. Perception of happiness consists of various factors such as personality, socioeconomic status, social network, time use and activities, stress exposure, and marital status and family [5]. Thus, previous studies used structured questionnaires such as the Oxford Happiness Questionnaire [60] and the Pemberton Happiness Index [61].

\section{Study limitations}

One of the limitations of this study is related to the study design: of eligible cancer survivors, those who were active enough to respond to the questionnaire at the time of the survey participated in the present study. Deteriorated SRHS, restricted physical functional capacity, depressive symptoms, and unhappiness of working cancer survivors might have been underestimated if working cancer survivors had participated less frequently than cancer-free workers, for instance, due to health concerns.

Another limitation is that, as already mentioned, our questionnaire items were incomplete to specify the duration of suffering from cancer, the cancer sites, and the cancer treatment. The subjects with "other cancer" must have included those with prostate, uterus, and thyroid cancers to some extent. A discussion we cannot conclude is whether the present findings could have been varied if the proportion of cancer sites had been different. For example, working cancer survivors could have experienced deteriorated SRHS, restricted physical functional capacity, depressive symptoms, and unhappiness more frequently if the proportion of prostate, uterus, and thyroid cancers, which generally expect a relatively good prognosis, had been lower. The incomplete data regarding the duration of suffering from cancer, the cancer sites, and the cancer treatment limit the discussion of their effect on working cancer survivors' SRHS, physical functional capacity, depressive symptoms, and happiness. However, our analysis of the nationwide data, which were heterogeneous in terms of the duration of suffering from cancer, the cancer sites, and the cancer treatment, enables us to clarify working cancer survivors' SRHS, physical functional capacity, depressive symptoms, and happiness and to compare to cancer-free workers at the national level. It contributes to revealing the national circumstance. Our study's purpose was not to examine the effects of a certain type of cancer on working cancer survivors' physical and mental characteristics. 


\section{Conclusions}

Even though cancer survivors were working, compared to workers without cancer history, they had a higher prevalence of deteriorated SRHS and restricted physical functional capacity. Continuous support to improve the SRHS and physical functional capacity of cancer survivors would be necessary for their better health even while they are working.

Supplementary Information The online version contains supplementary material available at https://doi.org/10.1007/s11764-020-00984-7.

Acknowledgments We would like to thank the participants and staff of the Japan Public Health Center-based Prospective Study for the Next Generation (JPHC-NEXT) protocol for their valuable contributions. The JPHC-NEXT members are listed at the following website (as of April 2018): https://epi.ncc.go.jp/jphcnext/en/members/index.html. We thank Editage Group (https://www.editage.jp/) for editing a draft of this manuscript.

Authors' contributions $\mathrm{AO}$ and $\mathrm{HY}$ conceived and all authors reviewed the study conception and design. KT, KS, KY, HI, NY, IS, TK, KA, YS, TS, TY, AG, M. Inoue, M. Iwasaki, NS, and ST contributed to data collection and preparation. AO, HY, and YL analyzed the data. All authors contributed to interpretation of results. AO and $\mathrm{HY}$ drafted and all authors critically revised the manuscript. All authors read and approved the final manuscript.

Funding This work was funded by the National Cancer Center Research and Development Fund (23-A-31 [toku], 26-A-2, 29-A-4, J-4) and the Japan Society for the Promotion of Science Grant-in-Aid for Scientific Research (C) (No. 16 K09111).

Data availability Investigators are granted access to JPHC-NEXT data after approval of the JPHC-NEXT Steering Committee and the Institutional Review Board. Please visit the following website for more information: https://epi.ncc.go.jp/jphenext/en/access/index.html

\section{Compliance with ethical standards}

Ethics approval The present study followed the Declaration of Helsinki. Informed consent was obtained from all individual participants. Approval was granted by the Institutional Review Boards of the National Cancer Center Japan and Fujita Health University.

Conflict of interest The authors declare that they have no conflict of interest.

Open Access This article is licensed under a Creative Commons Attribution 4.0 International License, which permits use, sharing, adaptation, distribution and reproduction in any medium or format, as long as you give appropriate credit to the original author(s) and the source, provide a link to the Creative Commons licence, and indicate if changes were made. The images or other third party material in this article are included in the article's Creative Commons licence, unless indicated otherwise in a credit line to the material. If material is not included in the article's Creative Commons licence and your intended use is not permitted by statutory regulation or exceeds the permitted use, you will need to obtain permission directly from the copyright holder. To view a copy of this licence, visit http://creativecommons.org/licenses/by/4.0/.

\section{References}

1. Foundation for Promotion of Cancer Research Japan (FPCRJ). Cancer statistics in Japan 2018. FPCRJ. 2019. https://www.fpcr. or.jp/pdf/p21/cancer_statistics_2018.pdf. Accessed 24 Nov 2020.

2. Zikos E, Coens C, Quinten C, Ediebah DE, Martinelli F, Ghislain I, et al. The added value of analyzing pooled health-related quality of life data: a review of the EORTC PROBE initiative. J Natl Cancer Inst. 2015;108:djv391. https://doi.org/10.1093/jnci/djv391.

3. Husson O, de Rooij BH, Kieffer J, Oerlemans S, Mols F, Aaronson NK, et al. The EORTC QLQ-C30 summary score as prognostic factor for survival of patients with cancer in the "real-world": results from the population-based PROFILES registry. Oncologist. 2020;25:e722-32. https://doi.org/10.1634/theoncologist.20190348 .

4. Centers for Disease Control and Prevention (CDC). Measuring healthy days: population assessment of health-related quality of life. CDC. 2000. https://www.cdc.gov/hrqol/pdfs/mhd.pdf. Accessed 24 Nov 2020.

5. Steptoe A. Happiness and health. Annu Rev Public Health. 2019;40:339-59. https://doi.org/10.1146/annurev-publhealth040218-044150.

6. Wikman A, Wardle J, Steptoe A. Quality of life and affective wellbeing in middle-aged and older people with chronic medical illnesses: a cross-sectional population based study. PLoS One. 2011;6:e18952. https://doi.org/10.1371/journal.pone.0018952.

7. Williams K, Jackson SE, Beeken RJ, Steptoe A, Wardle J. The impact of a cancer diagnosis on health and well-being: a prospective, population-based study. Psychooncology. 2016;25:626-32. https://doi.org/10.1002/pon.3998.

8. Jackson SE, Williams K, Beeken RJ, Steptoe A. Changes in health and wellbeing in the years leading up to a cancer diagnosis: a prospective cohort study. Cancer Prev Res. 2019;12:79-88. https://doi.org/10.1158/1940-6207.CAPR-18-0277.

9. Gupta D, Patel K, Lis CG. Self-rated health supersedes patient satisfaction with service quality as a predictor of survival in prostate cancer. Health Qual Life Outcomes. 2015;13:137. https://doi.org/ 10.1186/s12955-015-0334-1.

10. Zhu J, Wang F, Shi L, Cai H, Zheng Y, Zheng W, et al. Accelerated aging in breast cancer survivors and its association with mortality and cancer recurrence. Breast Cancer Res Treat. 2020;180:449-59. https://doi.org/10.1007/s10549-020-05541-5.

11. Ibrahim EM, Al-Homaidh A. Physical activity and survival after breast cancer diagnosis: meta-analysis of published studies. Med Oncol. 2011;28:753-65. https://doi.org/10.1007/s12032-0109536-x.

12. Friedenreich CM, Stone CR, Cheung WY, Hayes SC. Physical activity and mortality in cancer survivors: a systematic review and meta-analysis. JNCI Cancer Spectr. 2020;4:pkz080. https://doi.org/ 10.1093/jncics/pkz080.

13. Satin JR, Linden W, Phillips MJ. Depression as a predictor of disease progression and mortality in cancer patients: a meta-analysis. Cancer. 2009;115:5349-61. https://doi.org/10.1002/cncr.24561.

14. Ota A, Fujisawa A, Kawada K, Yatsuya H. Recent status and methodological quality of return-to-work rates of cancer patients reported in Japan: a systematic review. Int J Environ Res Public Health. 2019;16:1461. https://doi.org/10.3390/ijerph16081461.

15. Petersson LM, Wennman-Larsen A, Nilsson M, Olsson M, Alexanderson K. Work situation and sickness absence in the initial period after breast cancer surgery. Acta Oncol. 2011;50:282-8. https://doi.org/10.3109/0284186X.2010.533191.

16. Dahl AA, Fosså SD, Lie HC, Loge JH, Reinertsen KV, Ruud E, et al. Employment status and work ability in long-term young adult cancer survivors. J Adolesc Young Adult Oncol. 2019;8:304-11. https://doi.org/10.1089/jayao.2018.0109. 
17. Moskowitz MC, Todd BL, Chen R, Feuerstein M. Function and friction at work: a multidimensional analysis of work outcomes in cancer survivors. J Cancer Surviv. 2014;8:173-82. https://doi.org/ 10.1007/s11764-013-0340-4.

18. Bijker R, Duijts SFA, Smith SN, de Wildt-Liesveld R, Anema JR, Regeer BJ. Functional impairments and work-related outcomes in breast cancer survivors: a systematic review. J Occup Rehabil. 2018;28:429-51. https://doi.org/10.1007/s10926-017-9736-8.

19. Mikoshiba N, Miyashita M, Sakai T, Tateishi R, Koike K. Depressive symptoms after treatment in hepatocellular carcinoma survivors: prevalence, determinants, and impact on health-related quality of life. Psychooncology. 2013;22:2347-53. https://doi.org/ 10.1002/pon.3300.

20. Magyari F, Kósa K, Berecz R, Illés A, Miltényi Z, Simon Z, et al. Employment status and health related quality of life among Hodgkin-lymphoma survivors'- results based on data from a major treatment center in Hungary. Health Qual Life Outcomes. 2017;15: 180. https://doi.org/10.1186/s12955-017-0758-x.

21. Puigpinós-Riera R, Graells-Sans A, Serral G, Continente X, Bargalló X, Domènech M, et al. Anxiety and depression in women with breast cancer: social and clinical determinants and influence of the social network and social support (DAMA cohort). Cancer Epidemiol. 2018;55:123-9. https://doi.org/10.1016/j.canep.2018. 06.002.

22. Kato Y, Ota A, Yatsuya H, Li Y, Naito H, Fujisawa A, et al. Functional capacity, self-rated health status, and psychosocial characteristics of employed cancer survivors in Japan. Fujita Med J. 2017;3:55-61. https://doi.org/10.20407/fmj.3.3_55.

23. Berg Gudbergsson S, Fosså SD, Dahl AA. Is cancer survivorship associated with reduced work engagement? A NOCWO Study. J Cancer Surviv. 2008;2:159-68. https://doi.org/10.1007/s11764008-0059-9.

24. Ota A, Kawada K, Tsutsumi A, Yatsuya H. Cross-sectional association between working and depression prevalence in cancer survivors: a literature review. Environ Occup Health Practice. 2020;2: eohp.2020-0006-RA. https://doi.org/10.1539/eohp.2020-0006RA.

25. Sawada N, Iwasaki M, Yamaji T, Goto A, Shimazu T, Inoue M, et al. The Japan Public Health Center-based Prospective Study for the next Generation (JPHC-NEXT): study design and participants. J Epidemiol. 2020;30:46-54. https://doi.org/10.2188/jea. JE20180182.

26. The Ministry of Health and Welfare, Japan (MHWJ). The standards for the degree of independent living for elderly and disabled people. (Syougaikoureisya no Nichijoseikatsu Jiritsudo (Netakirido)). MHWJ; 1991. http://www.mhlw.go.jp/file/06-Seisakujouhou12300000-Roukenkyoku/0000077382.pdf. Accessed 24 Nov 2020. (written in Japanese).

27. Foebel AD, Pedersen NL. Genetic influences on functional capacities in aging. Gerontologist. 2016;56(Suppl 2):S218-29. https:// doi.org/10.1093/geront/gnw006.

28. Ishibashi T, Nishimura M, Yamada Y, Wakabayashi K, Koyano W. The criterion of independence in everyday life in relation to ADL and IADL. Jpn J Gerontol (Rounen Syakai Kagaku). 1998;20:42-9 (in Japanese).

29. Radloff LS. The CES-D scale: a self-report depression scale for research in the general population. Appl Psychol Meas. 1977;1: 385-401. https://doi.org/10.1177/014662167700100306.

30. Kohout FJ, Berkman LF, Evans DA, Cornoni-Huntley J. Two shorter forms of the CES-D (Center for Epidemiological Studies Depression) depression symptoms index. J Aging Health. 1993;5: 179-93. https://doi.org/10.1177/089826439300500202.

31. The ENRICHD Investigators. Enhancing recovery in coronary heart disease (ENRICHD) study intervention: rationale and design. Psychosom Med. 2001;63:747-55.
32. The ENRICHD Investigators. Enhancing recovery in coronary heart disease patients (ENRICHD): study design and methods. Am Heart J. 2000;139:1-9. https://doi.org/10.1016/s00028703(00)90301-6.

33. Cohen S, Williamson G. Perceived stress in a probability sample of the United States. In: Spacapan S, Oskamp S, editors. The social psychology of health. Newbury Park: Sage; 1988. p. 31-67.

34. Warttig SL, Forshaw MJ, South J, White AK. New, normative, English-sample data for the Short Form Perceived Stress Scale (PSS-4). J Health Psychol. 2013;18:1617-28. https://doi.org/10. $1177 / 1359105313508346$.

35. Cott CA, Gignac MAM, Badley EM. Determinants of self rated health for Canadians with chronic disease and disability. J Epidemiol Community Health. 1999;53:731-6. https://doi.org/10. 1136/jech.53.11.731.

36. Gadalla TM. Determinants, correlates and mediators of psychological distress: a longitudinal study. Soc Sci Med. 2009;68:2199-205. https://doi.org/10.1016/j.socscimed.2009.03.040.

37. Silver JK, Baima J, Newman R, Galantino ML, Shockney LD. Cancer rehabilitation may improve function in survivors and decrease the economic burden of cancer to individuals and society. Work. 2013;46:455-72. https://doi.org/10.3233/WOR-131755.

38. Cai J, Coyte PC, Zhao H. Determinants of and socio-economic disparities in self-rated health in China. Int J Equity Health. 2017;16:7. https://doi.org/10.1186/s12939-016-0496-4.

39. Caruso R, Nanni MG, Riba M, Sabato S, Mitchell AJ, Croce E, et al. Depressive spectrum disorders in cancer: prevalence, risk factors and screening for depression: a critical review. Acta Oncol. 2017;56:146-55. https://doi.org/10.1080/0284186X.2016. 1266090.

40. Ota A, Yatsuya H, Nishi N, Okuda N, Ohkubo T, Hayakawa T, et al. Relationships among socioeconomic factors and self-rated health in Japanese adults: NIPPON DATA2010. J Epidemiol. 2018;28(Suppl III):S66-72. https://doi.org/10.2188/jea. JE20170246.

41. Duijts SFA, van Egmond MP, Spelten E, van Muijen P, Anema JR, van der Beek AJ. Physical and psychosocial problems in cancer survivors beyond return to work: a systematic review. Psychooncology. 2014;23:481-92. https://doi.org/10.1002/pon. 3467.

42. Lovelace DL, McDaniel LR, Golden D. Long-term effects of breast cancer surgery, treatment, and survivor care. J Midwifery Womens Health. 2019;64:713-24. https://doi.org/10.1111/jmwh.13012.

43. Hamaker ME, Prins MC, Schiphorst AH, van Tuyl SA, Pronk A, van den Bos F. Long-term changes in physical capacity after colorectal cancer treatment. J Geriatr Oncol. 2015;6:153-64. https://doi. org/10.1016/j.jgo.2014.10.001.

44. O’Neill L, Moran J, Guinan EM, Reynolds JV, Hussey J. Physical decline and its implications in the management of oesophageal and gastric cancer: a systematic review. J Cancer Surviv. 2018;12:60118. https://doi.org/10.1007/s11764-018-0696-6.

45. Taxel P, Faircloth E, Idrees S, Van Poznak C. Cancer treatmentinduced bone loss in women with breast cancer and men with prostate cancer. J Endocr Soc. 2018;2:574-88. https://doi.org/10.1210/ js.2018-00052.

46. Sturgeon KM, Mathis KM, Rogers CJ, Schmitz KH, Waning DL. Cancer- and chemotherapy-induced musculoskeletal degradation. JBMR Plus. 2019;3:e10187. https://doi.org/10.1002/jbm4.10187.

47. Coumbe BGT, Groarke JD. Cardiovascular autonomic dysfunction in patients with cancer. Curr Cardiol Rep. 2018;20:69. https://doi. org/10.1007/s11886-018-1010-y.

48. Oikonomou E, Anastasiou M, Siasos G, Androulakis E, Psyrri A, Toutouzas K, et al. Cancer therapeutics-related cardiovascular complications. Mechanisms, diagnosis and treatment. Curr Pharm Des. 2018;24:4424-35. https://doi.org/10.2174/ 1381612825666190111101459 . 
49. Bjornard KL, Gilchrist LS, Inaba H, Diouf B, Hockenberry MJ, Kadan-Lottick NS, et al. Peripheral neuropathy in children and adolescents treated for cancer. Lancet Child Adolesc Health. 2018;2:744-54. https://doi.org/10.1016/S2352-4642(18)30236-0.

50. Yokoyama E, Kaneita Y, Saito Y, Uchiyama M, Matsuzaki Y, Tamaki T, et al. Cut-off point for the 11-item shorter form of the CES-D Depression Scale. Nihon Univ J Med. 2008;50:123-32.

51. Sakamoto N, Nanri A, Kochi T, Tsuruoka H, Pham NM, Kabe I, et al. Bedtime and sleep duration in relation to depressive symptoms among Japanese workers. J Occup Health. 2013;55:479-86. https:// doi.org/10.1539/joh.13-0074-oa.

52. Nakata A. Long working hours, job satisfaction, and depressive symptoms: a community-based cross-sectional study among Japanese employees in small- and medium-scale businesses. Oncotarget. 2017;8:53041-52. https://doi.org/10.18632/ oncotarget. 18084.

53. Ashing-Giwa K, Rosales M, Lai L, Weitzel J. Depressive symptomatology among Latina breast cancer survivors. Psychooncology. 2013;22:845-53. https://doi.org/10.1002/pon. 3084.

54. Yi JC, Syrjala KL. Anxiety and depression in cancer survivors. Med Clin North Am. 2017;101:1099-113. https://doi.org/10. 1016/j.mcna.2017.06.005.

55. Kawada T, Kuratomi Y, Kanai T. Depressive feelings, feelings of unhappiness, and subsequent psychological wellbeing among workers. Work. 2011;39:315-9. https://doi.org/10.3233/WOR2011-1179.

56. Shimai S, Yamamiya Y, Fukuda S. Subjective happiness among Japanese adults: an upward tendency associated with age. Jpn J
Public Health. 2018; 65: 553-62; https://doi.org/10.11236/jph.65. 9_553 (written in Japanese).

57. Kang D, Kim IR, Choi EK, Yoon JH, Lee SK, Lee JE, et al. Who are happy survivors? Physical, psychosocial, and spiritual factors associated with happiness of breast cancer survivors during the transition from cancer patient to survivor. Psychooncology. 2017;26:1922-8. https://doi.org/10.1002/pon.4408.

58. Sullivan J, Thornton Snider J, van Eijndhoven E, Okoro T, Batt K, DeLeire T. The well-being of long-term cancer survivors. Am J Manag Care. 2018;24:188-95.

59. de Camargos MG, Paiva BSR, de Oliveira MA, de Souza FP, de Almeida VTN, de Andrade CS, et al. An explorative analysis of the differences in levels of happiness between cancer patients, informal caregivers and the general population. BMC Palliat Care. 2020;19: 106. https://doi.org/10.1186/s12904-020-00594-1.

60. Hills P, Argyle M. The Oxford Happiness Questionnaire: a compact scale for the measurement of psychological well-being. Pers Individ Dif. 2002;33:1073-82. https://doi.org/10.1016/S0191-8869(01) 00213-6.

61. Hervás G, Vázquez C. Construction and validation of a measure of integrative well-being in seven languages: the Pemberton Happiness Index. Health Qual Life Outcomes. 2013;11:66. https://doi.org/10.1186/1477-7525-11-66.

Publisher's note Springer Nature remains neutral with regard to jurisdictional claims in published maps and institutional affiliations. 